\title{
Consumers in New Millennium: Attitudes towards Adoption of New Technologies in Purchasing Process ${ }^{1}$
}

\author{
Janka Kopaničová2 - Dagmar Klepochová3
}

\begin{abstract}
The use of new technologies has brought many changes into consumer behaviour, especially into purchasing process. The aim of the article is to uncover the attitudes of different generations towards usage of new technologies in purchasing process and determine if the diffusion of innovative purchasing process is significantly different among different generations. The article presents the results of authors' research of usage of new technologies in purchasing process, as well as attitudes towards it, among different age groups - Generation $X, Y, Z$ and seniors. Results of hybrid research carried out by semi-structured interviews with 551 respondents show, that there are significant generational differences in all three components of attitude towards online purchase, which can be - due to its characteristics-considered the most complex use of new technologies in purchasing process. Results prove that the diffusion of innovation in the purchasing process is significantly influenced by the age group. With age the number of Innovators significantly drops and the percentage of Laggards rises. The ratio of those adopting "early" and "late" significantly changes according to age group as well. Majority of younger respondents are accepting the new technologies into purchasing process early (Innovators, Early Adopters, Early Majority). Middle-aged consumers accept the innovations proportionally - copying the Roger's curve. Among seniors, the majority is "late" (Late Majority and Laggards).
\end{abstract}

\section{Key words}

Consumer Behaviour, Adoption, Diffusion Process, Attitudes, Generation X, Y, Z, Senior Citizens, New Technologies, Online Shopping

\section{JEL Classification: M31}

\section{Introduction}

Consumers in new Millennium have changed. More information about products, services and providers, faster approach to all needed data concerning quality, price, availability of products as well as information about previous customers' experience and a great number of choices where to buy - all of which is enhanced by consumers' access to new technologies - this all ultimately changes the overall consumer behaviour. A new technology is a common designation for several different products and

1 The paper is output of the project VEGA 1/0224/15 Consumer behavior and individual consumption in the periods of unemployment and relative deprivation of unemployed population: implications for decision taking bodies and business

2 Ing. Mgr. Janka Kopaničová, PhD.; University of Economics in Bratislava, Faculty of Commerce, Department of Marketing, Dolnozemská cesta 1, 85235 Bratislava, Slovakia; E-mail: jkopanicova@gmail.com

3 Ing. Dagmar Klepochová, PhD.; University of Economics in Bratislava, Faculty of Commerce, Department of Marketing, Dolnozemská cesta 1, 85235 Bratislava, Slovakia; E-mail: dklepochova@gmail.com 
services that currently create a new environment for online buying behaviour. New technologies (NT), just as any other "innovation" are subject to diffusion process and therefore the acceptance is different depending on various factors. According to several authors (Drábik, Rehák \& Žák, 2014; Obchod, 2013) usage of NT in purchasing process became an ordinary thing among young people, but the market consists of all age groups, therefore we felt the need to research what is the trend in population overall as well as in different age groups, represented by Generations $X$ (current middle age), Generation Y (current young generation), Generation Z (current teens and consumers in their early twenties) and Seniors.

Usage of new technologies changes the consumers' ways of purchasing of products and services. New technologies and their usage among population are subject to so called diffusion process - the process of accepting new ideas, products, and services - simply called adoption process of inventions. According to the theory of diffusion process (Rogers, 1962) all new ideas (usually appearing on the market as products) that bring something significantly new - so called innovations - are first accepted by small group of customers called Innovators. Innovators are usually very small group (according to Rogers (1995) only $2.5 \%$ of the market) that are willing to take risks, usually with high social status, financial resources and a close contact to scientific sources. According to Rogers (1962) their risk tolerance (closely related to their financial resources) allows them to adopt technologies that may ultimately fail. Soon after a bigger group (according to Rogers (1995) 13.5\% of the market) called Early Adaptors get familiar with the new idea. Early Adopters, have a higher social status, they are educated, with financial resources and social skills. According to Rogers (1962), they choose to adopt the innovation to help them to maintain a central communication position. When the Early Majority accept the innovation, the product is accepted by half of the market, as they represent one of the two largest groups of the market (according to Rogers (1995) - 34\%). People belonging to this group adopt an innovation after certain time - usually significantly longer than the previous groups. Early Majority have social status above average and they have contact with Early Adopters but they are rarely opinion leaders. The Late Majority represents the other largest group (34\% as well according to Rogers (1995)). They adopt an innovation later than the average consumer. These individuals are characterized by a high degree of scepticism, social status below average, limited financial resources, and lack of opinion leadership (Rogers 1962). The Laggards represent the rest of the market (16\% according to Rogers 1995). They are the last to adopt an innovation. These people typically do nor prefer nor seek new ideas, they are focused on "traditions", usually possess lowest social status, lowest financial resources.

According to Martinez, Polo and Flavián (1998) there are several significant differences between these groups. Rogers (1995) identified mostly the social status, financial and intellectual resources, but other authors (Mourali, 2014, Martinez, Polo \& Flavián 1998) consider personal characteristics and age as an important determinant as well.

Attitudes are according to some authors a core factor influencing the acceptance of new ideas - diffusion of innovation (Wang, Dou \& Zhou, 2008), therefore it is necessary to understand their content in a structured way (Crano \& Prislin, 2008). Several authors like Crano and Prislin (2008) Krech, Crutschfield and Ballachey (1968) and 
others see attitudes as a three factor concept. A three factor attitude theory sees the cognitive, affective and conative aspect in most of the complex attitudes.

Cognitive factor is represented by individual's thoughts, beliefs and ideas about the object of an attitude. The cognitive aspect can be based on gained information, previous experience or simply on social stereotypes.

Affective component - often also called emotional - consists of feelings or emotions about the object of the attitude, such as joy, fear, hate, love, anxiety, etc.

Conative, or so called behavioural component, represents individual's acting in a certain way - "towards to" or "away from" the object of the attitude.

The aim of the article is to uncover the attitudes of different generations towards usage of new technologies in purchasing process and determine if the diffusion of innovative purchasing process is significantly different among different generations.

\section{Methodology}

This paper presents results of the research study monitoring adoption of new technologies among different age groups and their impact on consumer behaviour, specifically on purchasing process. Data, which formed the basis for the analysis, were gathered in 2014. The hybrid research, whose partial results are reported, used method of semi-structured interviews that were conducted with more than five hundred respondents of Generations X, Y, Z and seniors from all regions of Slovakia. It was an interview based on prepared scenario where participants had opportunity to respond freely to questions monitoring their acceptance of new technologies (NT), their attitudes towards NT in purchasing process and perception of changes caused by NT in their consumer behaviour.

Interviews were conducted face to face - one researcher interviewed one participant - usually in their home environment. Data from semi-structured interviews were recorded and transcripted. Subsequently, transcripts were processed first individually (set of chosen "representative" interviews were analysed by qualitative analysis - forming codes using the GTM method), then all interviews ( $n=551)$ were analysed again (using the identified codes) and structured to give comparable results.

The research had the aim to answer the following research questions:

\section{Q1: What is current situation in usage and acceptance of NT in purchasing process?}

The use of NT in purchasing process is most noticeable in the level of acceptance of online shopping, therefore if researching the attitudes according to three factors theory, the most suitable is to focus on online shopping and find out:

Q2: What are the attitudes of Generations $X, Y, Z$ and seniors towards online shopping? Is there a significant difference in attitudes towards online shopping between Generations?

And researching diffusion process requires identifying: 
Q3: How does the adoption of usage of NT in purchasing process differ among Generations $X, Y, Z$ and seniors? Does age group, represented by generations, influence the innovativeness of the respondent?

Researching the usage and acceptance of NT at first, helps to determine the overall stage of acceptance of different NT features according to Roger's curve. Later the uncovering of differences in attitudes among researched age groups towards online shopping shows what are the sources of differences in the level of acceptance. The extent to which the consumer accepts innovative features brought by new technologies, determines the level of his innovativeness - analysing the results clustered according to the age group and comparing the results of generations using Pearson chi-square test shows, whether age group (generation) determines the consumer's level of innovativeness and if the diffusion process is significantly different among different generations.

\section{Results and Discussion}

The presented results are organized into three subsections to help to answer the research questions clearly.

\subsection{Usage and Acceptance of New Technologies in Purchasing Process}

The usage of New Technologies in purchasing occurs in different processes. The most significant and quite complex is online shopping. The standard shop is replaced by virtual store, products are represented by their pictures and verbal description, some products even offer possibility of trying a product sample (e-books, software), often there is a need of financial transaction happening online with the use of different new methods (such as PayPal, CardPay) and there is a need of computer, tablet or phone with internet connection during the purchase. The actual distribution usually happens after the purchase - with some products- like e-books, e-magazines, vouchers - there is no need of standard physical distribution, products can be immediately downloaded through the internet or automatically sent via internet to proper device (e.g. purchased e-books and e-magazines are automatically sent to Kindle - e-reader).

The current situation of NT use in purchasing process is described in Figure 1. The research results show that more than a half of respondents (50.5\%) have experience with online shopping in domestic shops. The experience with international online shops is less common (29\% respondents had experience with online shopping abroad). According to respondents, it is mostly because of the language barrier (shops are not in the language of the researched country - Slovak language), costs of physical distribution are higher (international postage usually exceeds the price difference firstly seen as an advantage of international online shop), the physical distribution takes longer time and of course, respondents perceive higher risk with international shops (mostly caused by anticipated complications in case of product return). Online purchases done with abroad sellers often have even more barriers - a payment method is the next one. Only one sixth (13.2\%) of respondents said they had PayPal account allowing to shop in some international e-markets or e-shops, and less than one third of 
respondents had experience with paying online with credit card (30.1\%). One fifth of the respondents had an experience with online shopping but no experience with online payment - they use only "pay cash on delivery" service - that represents $40 \%$ of all respondents with online shopping experience.

Figure 1 Purchase Related Usage of New Technologies

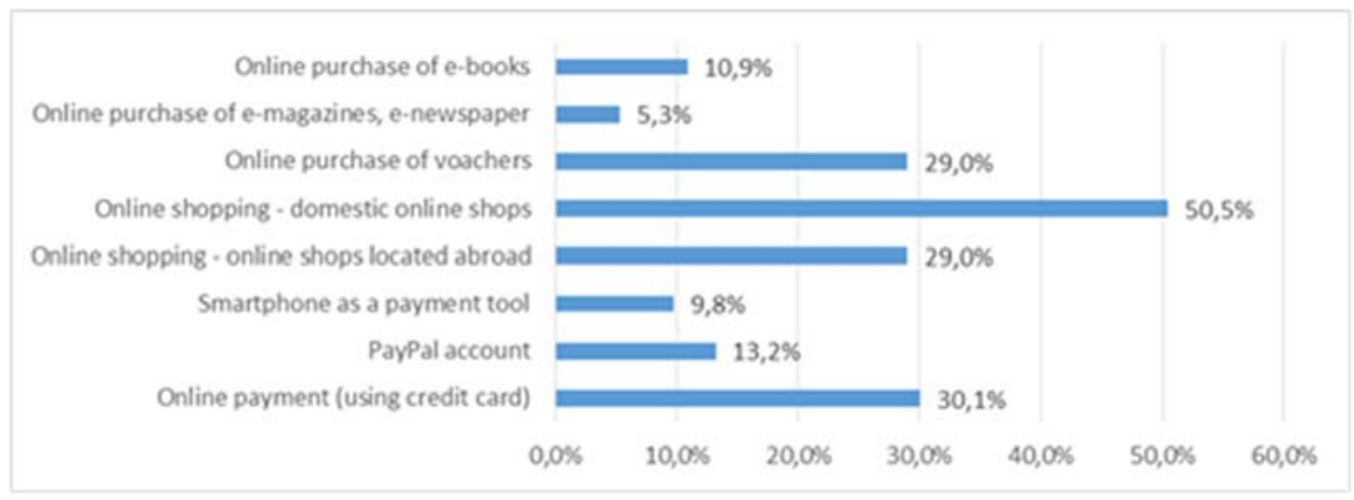

Source: Authors' research $(n=551$, year 2014)

Purchase of e-books and e-magazines, e-newspaper is rather unknown among many consumers. The experience with purchase of such kind had only less than $11 \%$ of respondents. More common and fast growing is purchase of online vouchers for services (29\%). Consumer purchases a voucher that allows him/her to use a certain service (very common) or purchase a product (much less common) at a special price. Vouchers are issued by an online company having agreements with service providers/product sellers. They are advertised, sold, paid and distributed online - usually paid using bank transfer (internet banking) or online credit card payment.

Usage of NT also appears in traditional - offline shopping. A payment with smartphone is an example of it as it employs two NT in once - a smartphone and a payment chip as well. Only $9.8 \%$ of respondents had an experience with such payment method.

\subsection{Attitudes of Different Age Groups Towards Online Shopping}

Online shopping - as said before - is the most complex representative of NT usage in purchasing. Therefore, researching this area requires looking at the attitudes towards online shopping using the "three aspects" perspective.

The first aspect is the cognitive component. Figure 2 shows the research results concerning perceived knowledge about online shopping. Knowing what it is, how it works, what are the rules and the risks - all the information that the respondents had were either perceived as sufficient or insufficient. Majority of youngest - teens currently called Generation Z (78.9\%) and young people Generation Y $(89.7 \%)$ claimed to have enough knowledge about online shopping and did not perceive a lack of information. On the other hand, only a half $(50.8 \%)$ of the middle-aged and approximately one of thirteen seniors (7.2\%) felt informed enough about all the matters needed to 
shop online. Although the concept of online purchase was totally unknown to only few individuals in younger generations, more than every second senior (54.8\%) did not know what it is and how it works. Analysing the differences by means of chi-square test showed that the there is a statistical significance $(n=551, p=0,000)$ and the differences between generations are not random.

Figure 2 Attitude towards Online Shopping (Cognitive Component)

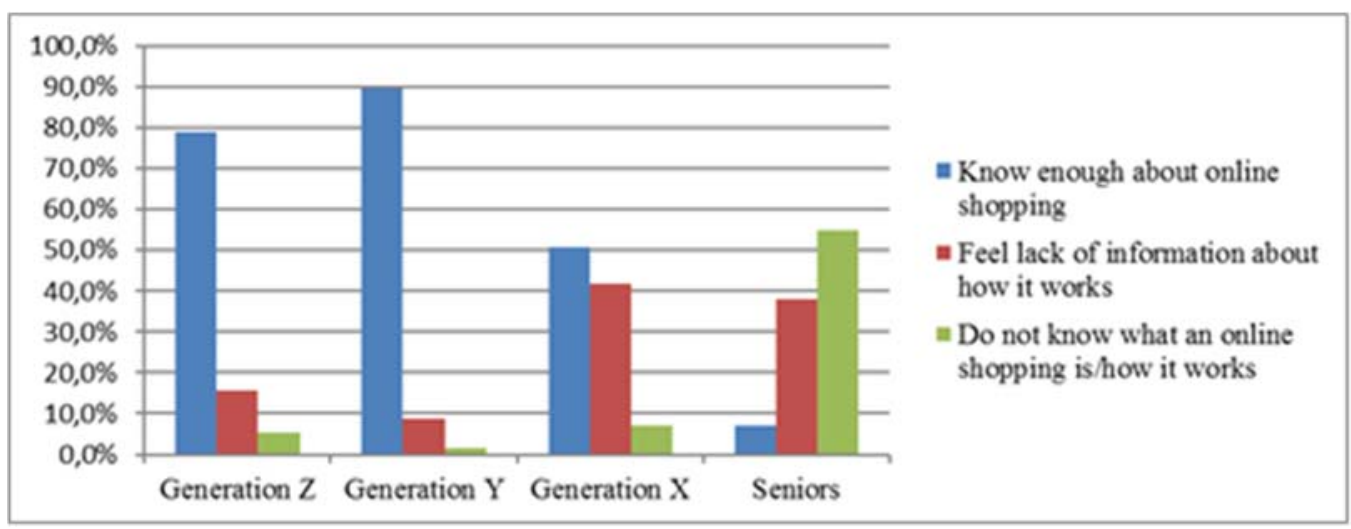

Source: Authors' research $(n=551$, year 2014)

Analysing the affective component, means uncovering what are the feelings of respondents towards online shopping. According to the theory, affective component of the attitude often has larger impact on the behaviour than the cognitive one; therefore, it is needed to understand not only what consumers think and know about the matter but also what they feel. The Figure 3 shows differences in perceiving security versus level of risk as well as trust and courage versus fear to shop online. As it is clear from the graph the fear rapidly rises with age. Among young people - Generations $Z$ and $Y$ the majority $(78.9 \%$ and $84.9 \%)$ felt that online shopping is secure, they had no fear to shop online and they felt confident to do so. Among middle-aged and senior respondents, the level of perceived risk rises. Less than every second middleaged (45.9\%) and only one of fifteen (6.6\%) respondents felt secure and confident to make online purchases. The group of those who had no feelings due to no interest in the object of attitude also rises with age. Among young people there were only few respondents that had no feeling about online shopping, because they were not interested in it (7\% in Gen Y, $13 \%$ in Gen Z) but almost two thirds (63.3\%) of seniors were not interested in it at all. These differences, tested by Pearson chi-square test are statistically significant $(n=551, p=0.000)$. 
Figure 3 Attitude towards Online Shopping (Affective Component)

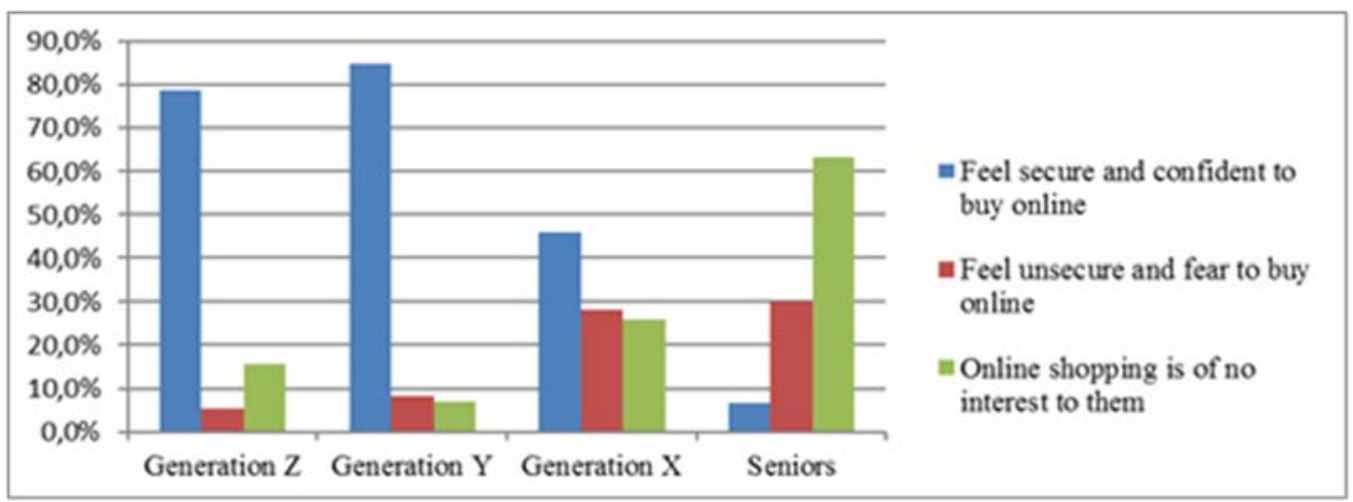

Source: Authors' research $(n=551$, year 2014)

The cognitive and affective components influence and form the conative component- that is usually representing the pattern of behaviour. Researching the behavioural component means uncovering what are the intentions and what is the actual behaviour. Figure 4 shows differences between generations. As it is apparent from the figure, among seniors, majority (88\%) had no intention to shop online. A small group - all together $6 \%$ had rare, some or quite large experience with online shopping and $5.4 \%$ of senior respondents were thinking about shopping online in the future. Compared to this, only approximately one of thirty respondents (3.2\%) from Generation $Y$ (young people in their later twenties and earlier thirties) had no intention to buy online. The rest were either thinking of doing it in the future (2.2\%) or were shopping online to a certain extent- some rarely $(14.1 \%)$, others more often $(41.1 \%)$.

Figure 4 Attitude towards Online Shopping (Behavioural Component)

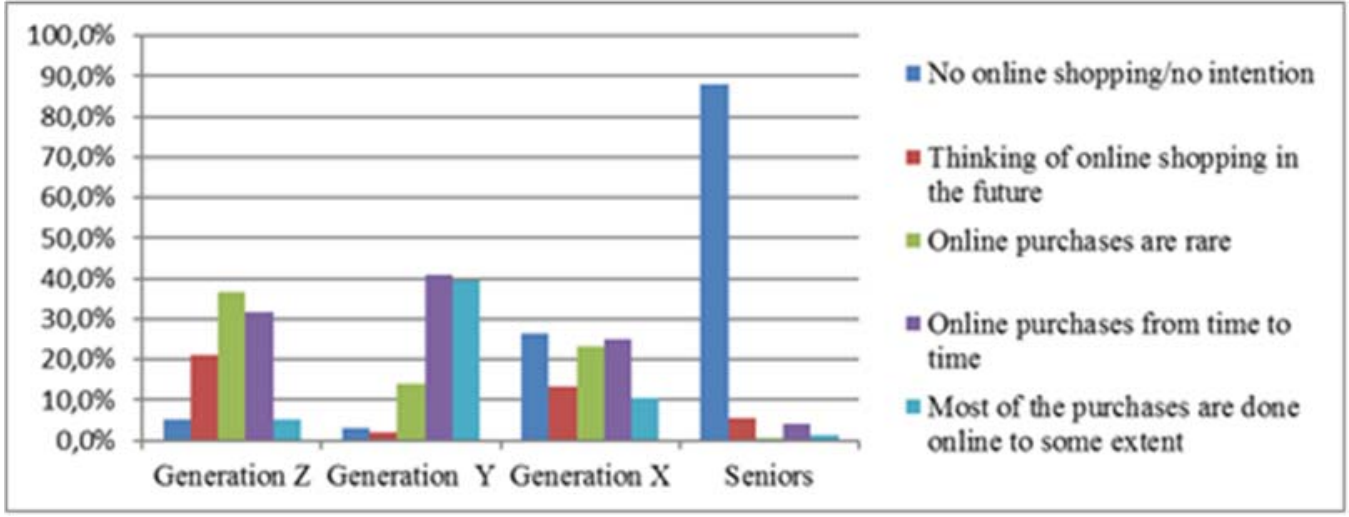

Source: Authors' research $(n=551$, year 2014)

More than one third of this generation (39.5\%) did most of their purchases online to some extent (if it was not possible to realize the whole purchase online, they used internet to find the suitable product, compare prices, review the experiences of other consumers with the products and sellers, find and contact the suitable offline shop, 
etc.). Differences appearing in the graph were tested by Pearson 's chi-square test and showed the statistical significance $(n=551, p=0,000)$.

All three components of attitudes are significantly different between generations. The older the respondent the less accepting NT in purchase process he/she is.

\subsection{Adoption of Usage of New Technologies in Purchasing Process}

According to how many features representing the NT the respondent uses and according to how "new" and "accepted" the features are, we divided the respondents in groups according to Roger's diffusion curve. Innovators - Early Adopters - Early Majority - Late Majority- Laggards. Figure 5 shows the percentage of each of the groups among generations. Generation $Z$ has no Laggards and highest percentage of Innovators $(26.3 \%)$. Generation $Y$ has majority of respondents in the phase of Innovators (18.4\%), Early Adopters (30.3\%) and Early Majority (38.9\%). Generation X is closest to the original Roger's curve with only 3,3\% of Innovators, $11,6 \%$ of Early Adopters, $28.7 \%$ of Early Majority and $56,4 \%$ of those who accept the innovation late (Late Majority and Laggards). As expected, the majority of older generation (60+ years) belongs to Laggards (77.1\%) and "the early half" is among seniors represented only by $7.8 \%$ of respondents. Testing the results by Pearson chi-square test showed that the differences are statistically significant $(n=551, p=0,000)$.

Figure 5 Adoption of New Technologies in Purchasing Process among Generations

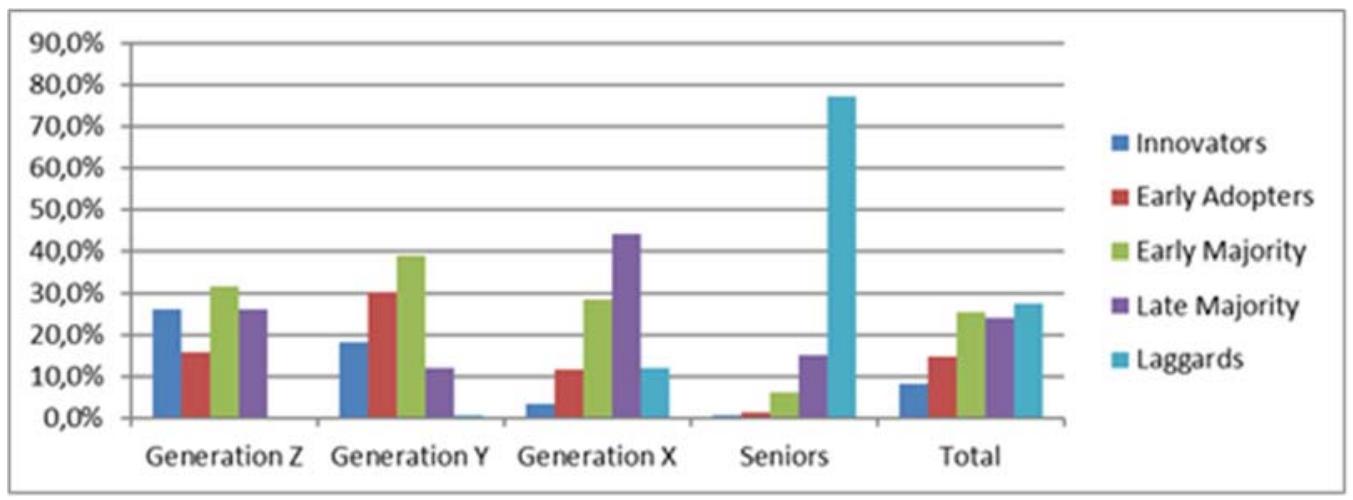

Source: Authors' research $(n=551$, year 2014)

\section{Conclusion}

Results obtained from the research show that the usage of NT in purchasing process is currently accepted by $50.5 \%$ of all respondents. Considering the content of the sample (all generations and all regions proportionally) the acceptance of innovative way of purchasing is already accepted by the Early Majority and only to be accepted by the Late Majority. 
Online purchases of e-products such as e-books or e-newspapers are still in phase of "Early Adopters" as only less than $11 \%$ of respondents had an experience with buying e-book, and even less e-magazine or e-newspaper.

Online purchases of e-vouchers (most of the time vouchers are representing services) is more common - as vouchers usually offer high price reductions that attract consumers. It is a fast growing segment, often attracting even consumers without previous online purchase experience. Currently are e-vouchers being accepted by Early Majority (29\% of the respondents).

Involving NT in traditional - offline purchase is represented by a smartphone payment that is currently, according to the results, in the "Early Adopters" phase.

Attitudes of different age groups - currently represented by Generations $X, Y, Z$ and seniors are significantly different. The younger the respondent the more informed, more opened, less fearful and more innovative he/she tends to be.

The age is a factor influencing the adoption of new technologies into the purchasing process. The older the consumer, the less probable the early adoption is. Younger age groups are leaders in adopting the new technologies into their purchasing process. The middle-aged are the subject to "standard Roger's diffusion process curve" and the most of the older people are avoiding innovations in their purchasing process. Despite this fact, there is a group of approximately $10 \%$ of seniors, who are willing to implement more of new technologies into their consumer behaviour; therefore, there is a space for informing, explaining and motivating.

\section{References}

Crano, W. D., \& Prislin, R. (2008). Attitudes and Attitude Change. New York: Psychology Press.

Drábik, P., Rehák, R., \& Žák, Š. (2014). New trends of digital marketing in retail. In Current challenges of marketing and their application in practice: scientific articles from the international conference: 3 April 2014 (pp. 119-127). Prague, Czech Republic. Zlín: Radim Bačuvčík - VeRBuM,

Krech, D., Crutchfield, R. S., \& Ballachey, E. L. (1962). Individual in Society. New York: McGraw Hill.

Martinez, E., Polo, Y., \& Flavián, C. (1998). The acceptance and diffusion of new consumer durables: differences between first and last adopters. Journal of Consumer Marketing, 15(4), 323-342.

Mourali, M. (2014). Consumer Adoption of New Products: Independent Versus Interdependent Self-Perspectives. Journal of Marketing, 78(2), 101-117.

Obchod. (2013). Online nakupovanie sa stalo štandardom. Obchod : maloobchod, vel'koobchod, distribúcia, 2013(9), 20-21.

Rogers, E. M. (1962). Diffusion of Innovations. Glencoe: Free Press.

Rogers, E. M. (1995). Diffusion of Innovations. New York: Free Press. 
Wang, G., Dou, W., \& Zhou, N. (2008). Consumption attitudes and adoption of new consumer products: a contingency approach. European Journal of Marketing, 42(1-2), 238-254. 